\title{
PENGARUH KOMPENSASI DAN DISIPLIN KERJA TERHDAP KINERJA KARYAWAN PADA PT. HADJI KALLA CABANG PALU
}

\author{
ASTRIT NANCY \\ HARNIDA WAHYUNI ADDA \\ MOH. ALI MURAD \\ Program Studi S1 Manajemen, Fakultas Ekonomi, Universitas Tadulako \\ Email: astritnancy@gmail.com; harnidaadda@gmail.com; alimrdplw@gmail.com;
}

\begin{abstract}
This study ainst o determine and analyze the effeck of compensation and work discliplineon employee performance of at PT. Hadji Kalla Branch Palu. The population in this studyt were all employees of PT. Hadji Kalla Palu Branch, amounting to 46 employees, the entire population made as respondents (census). This study usesdescriptive descriptive data analysis with a quantitative approach that uses multiple linear regression analysis techniques. The result of this study day that compensation and work discipline have a positive and significant effect on employee performance at PT. Hadji Kalla Palu Branch.
\end{abstract}

Keywords: Compensation, Work Discipline, Employee Performance

\begin{abstract}
ABSTRAK
Penelitian ini bertujuan untuk mengetahui dan meganalisis pengaruh kompensasi dan disiplin kerja terhadap kinerja karyawan pada PT. Hadji Kalla Cabang Palu. Populasi dalam penelitian ini ialah seluruh karyawan PT. Hadji Kalla Cabang Palu yang berjumlah 46oerang karyawan, seluruh populasi dijadikan responden (sensus). Penelitian ini memakai analisis data deskriptif dengan pendekatan kuantitatif yang memakai kuisioner sebagai alat pengumpul data dan memakai analisi regresi linar berganda. Hasil pnelitian ini mengatakanbahwa kompensasi \&disiplin kerja berpengaruh positif \& signifikan terhadap kierja karywan pada PT.Hadji Kalla Cabang Palu.
\end{abstract}

Kata kunci: Kompensasi, disiplin kerja, kinerja

\section{PENDAhUluan}

Sumber daya manusiamempunyai pemikiran persaan akal, kemauan, keterampilan, ilmu pengetahuan, motivasi karya ( rasio, rasa dan karsa) dan daya. Seluruh kemampuan SDM itu memiliki pengaruh terhadap usaha dalam perusahaan dalam mencpai keinginan. Walaupun berkembangnya teknologi, perkembangan informasi, terdapat modal dan madainya bahan, bila tidak ada SDM susah untuk organisasi tersebut untuk menggapai suatu tujuan (Sutrisno, 2009).

PT. Hadji Kalla Cabang Palu ialah perusahaan yang berjalan pada bidang mobil Toyota yangberalamatdi JlnJuandaNo45,yang terus mengarah pada visi dan misi untuk menjadi organisasi yang professional dan baik dengan meningkatkan pelayanan pada distributor dan pelanggan agar dapat mencapai tujuan perusahaan. PT Hadji Kalla terus berusaha meningkatkan dan mengembangkan kinerja para karyawan yang tidak terlepas dari dorongan sumber daya manusia yang memiliki kualitas yang bias menggerakkan roda usaha lewat distributor yang tersebar diseluruh wilaya Indonesia yang mendapat dukungan oleh prasarana dan sarana.

Ada beberapa faktor yang menjadi perhatian dalam kaitannya dengan kinerja karyawan, diantaranya mengenai kompensasi seperti, bonus yang diberikan perusaahaan kepada karyawan berbeda-beda sesuai dengan tingkat jabatan dan lama bekerja.Pemberian kompensasi kepada karyawan pada PT.Hadji Kalla masih dirasakan belum memenuhi tingkat kepuasan dari sebagian karyawan, hal ini dapat dilihat pada bagian sales, pemberian bonus dan fasilitas yang diberikan pada sales masih kurang, seperti saat pencapaian target penjualanKemudian usaha lain yang bias dilakukan organisasi agar meningkatkan kinerja karyawan ialah dengan cara memperhatikan tingkat kedisiplinan pada karyawan dalam bekeja. Tingkat Kedisplinan pada PT. Hadji Kalla masih perlu ditingkatkan lagi, hal ini juga dapat dilihat masih terdapat karyawan yang belum menaati disiplin kerja . Seperti, masih 
ditemukannya karyawan datang terlambat sehingga pekerjan yang seharusnya dilakukan dapat tertunda, dan juga masih ada beberapa karyawan yang tidak mengikuti briefing yang diadakan setiap pagi sebelum para karyawan menjalankan pekerjaannya. Masalah seperti ini akan mempengaruhi kinerja karyawan dalam bekerja.Apabila pemenuhannya tidak sesuai dengan prosedur yang ditetapkan oleh organisasi berikutnya. belum sesuai dengan prosedur yang diinginkan oleh perusahaan sebelumnya. Adapun penelitian ini memiliki tujuan untuk mencari tahu dan menganalisis pengaruh kompensasi dan disiplin kerja terhadap kinerja karyawan pada PT. Hadji Kalla Cabang Palu baik secara serempak ataupun parsial.

\section{KAJIAN LITERATURE DAN PENEGEMBANGAN HIPOTESIS}

Definisi kinerja Mangkunegara (2009) apabila kinerja karyawan (prestasi kerja) secara kuantitas dan kualitas yang di gapai oleh seorang karyawan dalam melakukan pekerjaannya sesuai dengan tanggung jawab yang ditugaskan kepadanya. Mencapai kinerja secara kuantitas dan kualitas, maka perusahaan harus memberikan sistem kompensasi yang adil bagi karyawannya.Hasibuan (2014) Kompensasi ialahseluruh pemasukan yang menyerupai uang atau barang yang tidak langsung maupun langsung di terima karyawan sebagai upah atas jasa yang dikasih kepada organisasi. Menurut Dessler (2009), kompensai karyawan ialah bentukimbalan yangdiberikan kepada karyawan dan dari didikerjakan karyawan tersebut. Jika organisasi memberikan tambahan kompensasi kepada karyawan, maka karyawan cenderung mau berusaha untuk memeberikan performa kinerjanya. Apabila karywan merasa imblan yang sudah diterima berbanding dengan pelayanan yang diterima pada perusahaan, jadi karyawan akan berusaha untuk mempertahankan bahkan untuk mencapai kinerjanya disuatu hari. Selain itu, untuk meningkatkan kinerja karyawan ialah dengan penerapan disiplin kerja yang sesua dengan prosedur..

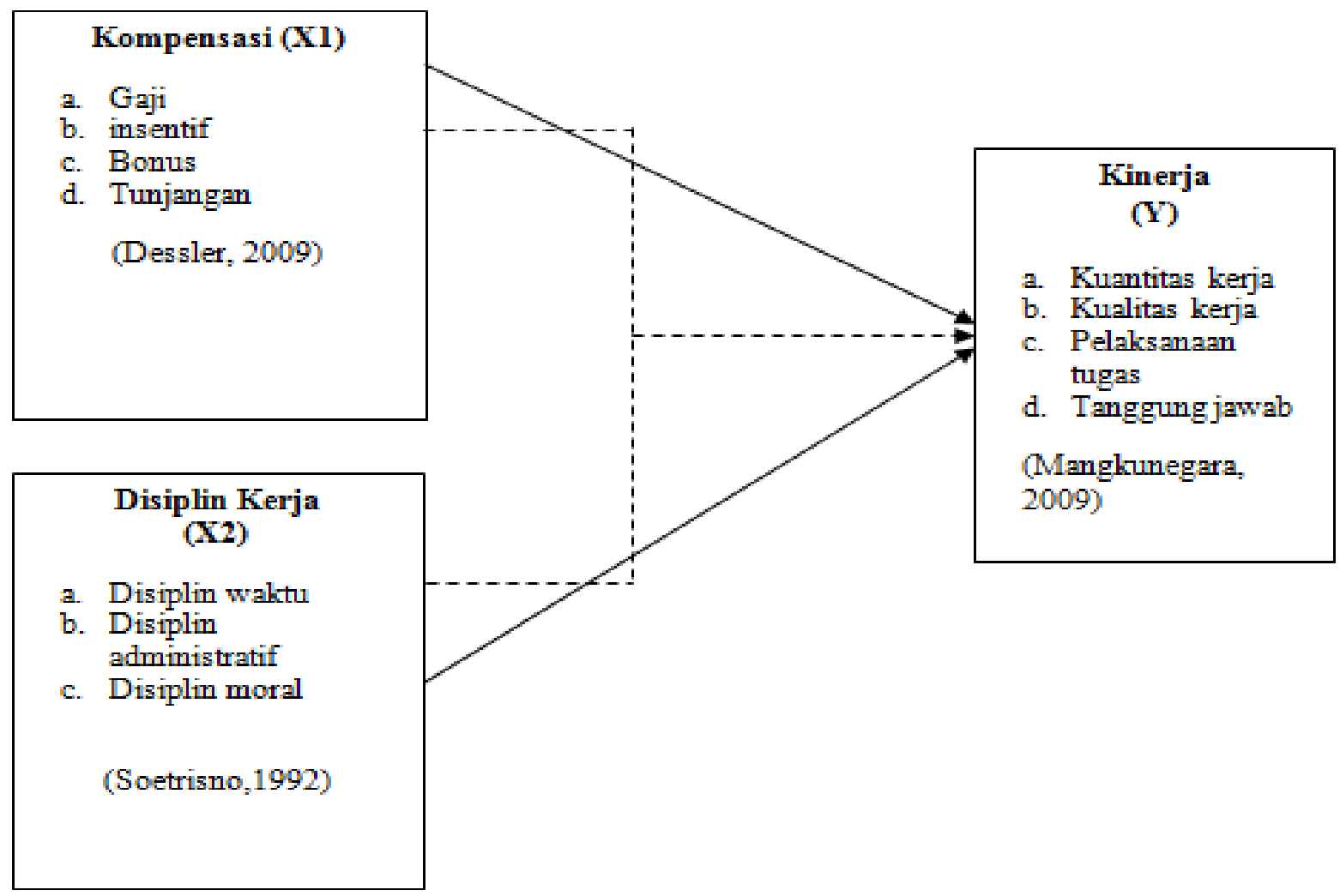

Gambar 1. Kerangka Pemikiran Penelitian

Keterangan Pengaruh SecaraSerempak

Pengaruh Secara Parsial 
Berdasarkan permasalahan dan kerangka konseptual penelitian yang sudah dijelaskan di atas maka bisa diajukan hipotesis penelitian sebagai berikut :(1) Variabel kompensasi dan disiplin kerja secara serempak berpengaruh signifikanb terhadap kinerja karyawan PT. Hadji Kalla Cabang Palu (2) Variabel kompensasi secara parsial bepengaruh signifikan terhadap kinerja karyawan PT. Hadji Kalla Cabang Palu (3) Variabel disiplin kerja secara parsial berpengaruh signifikan terhadap kinerja karyawan PT. Hadji Kalla Cabang Palu.

\section{METODE PENELITIAN}

Data yang dipakai dalam penelitian ini ialah sebagai berikut: (1) Data kualitatif, ialah data yang menyerupai kata, skema dan gambar dan data yang berkumpul menyerupai kata, agar tidak ditekankan pada angka. (2) Data kuantitatif, ialah data yang menyerupai angka atau data kualitatif yang diangkakan. Data kualitatif yang diangkakan contohnya yang ada dalam skala yang diukur (skoring: sangat setuju $=5$, setuju $=4$, ragu-ragu $=3$, tidak setuju $=2$, dan sangat tidak setuju = 1) Sugiyono (2014:15). Sumber data yang digunakan dalam penelitian ialah data primer dan data sekunder, (Sugiyono (2014:137) menerangkan bahwa:(1) Data primer, data yang didapatkan penulis secara langsung dari PT.Hadji Kalla Cabang Palu melalui observasi, wawancara maupun daftar pertanyaan.(2)Data sekunder, Data penunjang yang bersangkutan dengan penelitian yang bersumber dari data primer yang sudah dilakukan lebih dahulu dan dipersiapkan oleh pihak yang mengumpulkan dat primer oleh pihak lainyang terkait dengan penulisan ini yakni, PT.Hadji Kalla Cabang Palu.

Popilasi dalam penelitian ini ialah semua karyawan PT.Hadji Kalla Cabang Palu yang mempunyai jumlah 46 orang karyawan, seluruh populasi dijadikan responden (sensus). Sensus aialah cara mengambil data dari populasi dengan menjadikan keseluruhan anggota populasi itu untuk diambil datanya. Langkah-langkah dalam pengumpulan data yakni, Observasi dengan cara melakukan mengamati terhadap tingkah laku subjek yang sementara diamati selaanjutnya dilaksanakan penulisan meengenai apa yang sementara diamati. Peneliti melakukan pengamatan tentang apa saja yang berkaitan dengan kompensasi dan disiplin kerja terhadap skinerja karyawan pada PT. Hadji Kalla Cabang Palu.Wawancara ialah cara yang digunakan peneliti untuk mendapatkan informasi berkaitan variabel yang diteliti dengan cara bertanya menjawab pertanyaan secara singkat bersama karyawan. Dalam penelitian ini peneliti mewawancarai secara langsung pimpinan dan sebagian karyawan di PT. Hadji Kalla Cabang Palu yang berhubungan dengan kompensasi dan disiplin kerja terhadap kinerja karyawan.Memakai teknik wawancara teratur sesuai dengan kuesioner yang sudah dipersiapkan. Kuesioner ialah melakukan mengumpulkan data dengan cara membagikan beberapa data pertanyaan/ungkapan yang teratur kepada karyawan PT. Hadji Kalla Cabang Palu mengenai seputar kompensasi dan disiplin kerja serta kinerja karyawan. Teknik ini dipakai untuk mengingat kuesioner memiliki poin lebih karena bisa diukur tingkat konsistennya juga kesahaan setiap poinnya. Sifat kkuesioner yang dipakai ialah kuesioner tertutup deangan cara memberikan peryantaan/pertanyaan yang sudah disediakan berbagai pilihan jawaban. Dokumentasi yaitu melakukan pengambilan datayang didapatkan dari berbagai dokumen-dokumen ayang ada pada perusahaan atau catatan-catatan yang tersimpan, buku dan lain-lain yang digunakan berkaitan dengan penelitian yang dilakukan di PT. Hadji Kalla Cabang Palu. Penyusunan instrumen penelitian harus mencari tahu dan paham mengenai jenis skala yang diukur dan tipe-tipe skala pengukuran supaya instrument dapat dukur sesuai dengan keingnan yang mau diukur dan dapat dipercaya serta reliabel (konsisten) terhadap permasalahn instrument Riduwan ( 2005). Berdasarkan indikator-indikator dari variabel tersebut, Berdasarkan indikator - indikator dari masing masing variabel, akan diukur memakai daftar pernyataan atau kuisioner. Skala yang dipakai dalam pengukuran dalam kuisioner ialah skala likert dipakai untuk 
mengukur tingkah laku, persepsi dan pendapat atau kumpulan orang mengenai fkejadian fakta sosial. Sugiyono (2014:133).Pengukuran variabel untuk menilai seberapa besar tingkat persetujuan dan tidak setuju yang dirasakan oleh responden dengan 5 (lima) kategori yang ada pada tabelberikut ini:

Tabel 3. Skala Pengukuran Likert

\begin{tabular}{lll} 
No & Alternatif & Pemberian Skala/skor \\
\hline 1 & Sanagt setuju (SS) & 5 \\
2 & Setuju (S) & 4 \\
3 & Ragu-Ragu (R) & 3 \\
4 & Tidak Setuju (TS) & 2 \\
5 & Sangat Tidak Setuju (STS) & 1 \\
\hline
\end{tabular}

Sumber: Sugiyono (2014)

Suatu skala pengukuran dikatakan benar apa bila ditemukan peersamaan antar data yang didapatkan dengan data yang sebenarnya terjadi pada objek penelitian. Selanjutnya valid berarti instrumentersebut bisa dipakai untuk mengukur apa yang sebaiknya diukur, Sugiyono (2014).Setelah kuisioner diisi oleh karyawan dan sudah terkimpul kebali,selanjutnya peneliti menentukan validitasnya dengan menggunakan bantuan SPSS. Uji validitas adalah pengujian alat pengumpulan data berupa daftar pernyataan. Uji validitas digunakan untuk mengetahui keabsahan dan kebenaran penelitian. Program SPSS relase 20 digunakan untuk menguji valid tidaknya setiap item yang ada, menurut Sugiyono (2014) apa bila kolerasi dibawah 0,30, maka bisa disimpulkan bahwa setiap instrumen tersebut tidak dapat valid, sehingga harus dibuang atau diperbaiki. jika kolerasi sama dengan 0,30 atau lebih dan tingkat kolerasinya lebih tinggi dan positif, maka setiap instrumen dikatakan valid. sedangkan uji realibilitas menurut Sugiyono (2009:), menyatakan bahwa instrumenyang reliable ialah instrument yang apa bila dipakai berulang ulang untuk mengukur objek yang sama, akan mendapatkan hasil yang serupa.Mengetahui reliabilitas adalah dengan dibandingkan nialai $r$ hasil dengannilai kontanta $(0,60)$, yakni jika nilai $r$ hasil > konstanta 0,60 , maka pernyataan tersebut reliable.

Pengujian normalitas dilakukan memakai grafik histogram dan normal probalityplot dengan mengetahui titik tersebarnya pada sumbu diagonal.

Formulasi persamaan regresi linear berganda sebagai berikut:

$$
\mathbf{Y}=\boldsymbol{\alpha}+\mathbf{b}_{1} \mathbf{X}_{1}+\mathbf{b}_{2} \mathbf{X}_{2+}
$$

Dimana:

Y= kinerja

A $=$ kontanta

$\mathrm{X}_{1}=$ kompensasi

$\mathrm{X}_{2}=$ disiplin kerja

$\mathrm{b}=$ koefisien regresi

Tujuan digunakannya metode ini adalah untuk mengukur dan dan menjelaskan hubnungan liniear antara variabel independen kepada variabel dependen, yaitu melihat pengarih kompensasidan displinkerja terhadap kinerja karyawan. Bila $\mathrm{F}_{\text {hitung }}>\mathrm{F}_{\text {tabel }}$ pada tingkat kepercayaan $95 \%(\alpha=0,05)$ akan membuktikan semua yang dicermati secara serempak berpengaruh nayta variabel tidak bebas. Jika $F_{\text {hitung }}<\mathrm{F}_{\text {tabel }}$ pada tingkat kepercayaan $95 \%(\alpha=0,05$ jadi membuktikan seluruh variabel bebas yang diamati secara serempak tidak berpengaruh nyata terhadap variabel tidak bebas.Jika $t$ hitung $>t$ tabel pada tingkat kepercayaan $95 \%(\alpha=0,05)$ jadi membuktikan seluruh variabel independent $(\mathrm{X})$ yang diamati mempunyai pengaruh yang signifikan terhadap variabel dependent (Y). Jika $t_{\text {hitung }}<\mathrm{t}$ tabel pada tingkat kepercayaan $95 \%(\alpha=0,05)$ jadi membuktikan variabel independent $(\mathrm{X})$ yang diamati 
belum memiliki pengaruh yang signifikan terhadap variabel dependen (Y). Pengambilan hipotesis yang dilakukan dengan melihat kriteria: (1) jika nilai signigikansi > 0,05 maka keputusanaya menerima Ho dan menolak Ha. (2) jika nilai signifikansi < 0,05 jadi keputusannya ialahmenerima Ha dan menolak Ho.

Uji $\mathrm{F}$ dipakai untuk mencari tahu tingkat signifikan pengaruh variabel-variabel independen secraserempak terhadap variabel. Uji $\mathrm{F}$ dipakai dengan cara membandingkan $\mathrm{P}$ (probability)dengan $\alpha$ $=5 \%$. Uji F (serempak) akan dilihat pada tabel ANOVA (Analiysis of Varians) pada hasil pengolahan data melalui SPSS.Penelitian ini,. Hi[otesis yang dipakai dalam penelitian ini ialah: (1) apabila signifikansi $\mathrm{F}>0,05$ maka variabel - variabel bebas yakni kompensasi dan disiplin kerja, tidak berpengaruh secara signifikan dan serempak terhadap variabel terikat (Kinerja). (2) apabila signifikansi $\mathrm{F}<0,05$ maka variabel-variabel bebas yakni, kompensasi dan disiplin kerja berpengaruh secara signifikan dan serempak terhadap variabel terikat (Kinerja).

Uji t parsial dipakai untuk mencari tahu masing-masing variabel independen secara parsial memiliki pengarug sigifikan terhadapveriabel dependen .

\section{HASIL DAN PEMBAHASAN}

Uji Validitas dilakukan Hasjrat Abadi Kota Palu dengan mengambil 23 orang, didapatkan bahwa semua item pertanyaan yang diberikan pada kuesioner penelitian selurunya dinyatakan valid. Hal ini ditunjukkan dengan nilai Corrected Item Total Correlation lebih besar dari 0,3 ( $\mathrm{r} \geq 0,3)$ dan tidak bernilai negatif. Berdasarkan perhitungan program SPSS, jadi bisa disimpulkan bahwa semua variabel penelitian dalam instrumen penelitian (kuesioner) mendapatkan nilai konsistensi atau reliabel yang layak karena memenuhi standar koefisien Alpha Cronbach 1 lebih besar dari 0,6 $(\alpha \geq 0,6)$ (Sugiyono, 2009:173).

Tabel 2. Uji Realibilitas

\begin{tabular}{lccc}
\multicolumn{1}{c}{ Variabel } & Cronbach'Alpha & Konstanta & Status \\
\hline Kompensasi (X1) & $\mathbf{0 , 8 7 0}$ & $\mathbf{0 , 6 0}$ & Reliabel \\
Disiplin kerja (X2) & $\mathbf{0 , 8 7 5}$ & $\mathbf{0 , 6 0}$ & Reliabel \\
Kinerja (Y) & $\mathbf{0 , 8 8 3}$ & $\mathbf{0 , 6 0}$ & Rerliabel \\
\hline Sumber : data diolah SPSS & & &
\end{tabular}

Berdasarkan perhitungan program SPSS, jadi bisa disimpulkan semua variabel penelitian dalam instrumen penelitian (kuesioner) mendapatkan nilai konsistensi atau reliabel yang layak karena bisa memenuhi standar koefisien Alpha Cronbach lebih besar dari 0,6 ( $\alpha \geq 0,6)$ Sugiyono,(2009).

Tabel2.Uji multikolinieritas

\begin{tabular}{cccc}
\hline \multirow{2}{*}{ Variabel Independen } & \multicolumn{2}{c}{ Colinierty Statictic } & Keterangan \\
\cline { 2 - 3 } & Tolerance & VIF & Non Multikolinearitas \\
\hline Kompensasi & 0.998 & 1,002 & Non Multikolinearitas \\
Disiplin Kerja & 0.998 & 1,002 & \\
\hline
\end{tabular}


Sumber : data diolah SPSS

Berdasarkan tabel di atas bisa disimpulkan bahwa semua variabel independen (kompensasi, dan disiplin kerja) memiliki nilai VIF $<10$ sehingga tidak terjadi multikolinieritas diantara variabel independen.

Berdasarkan hasil uji multikolonearitas yang telah dilakukan, bisa ditahu bahwa tolerance memperlihatkan tidak adanya variabel independen yang mempunyai nilai lolerance kurang dari 0,10yang berarti tidak ada kolerasi antar variabel.Hasil dari penjumlahan variance inflation factor (VIF) juga meberikan hal yang sama.yakni, tidak ada variabel independen yang mempunyai nilai VIF lebih dari 10, dengan demikian, asumsi multikolonearitas dalam model regresi yang ditgunakan terpenuhi, maka semua variabel memenuhi kriteria dan analisis dapat dilanjutkan

Penyusunan deskripsi variabel merupakan distribusi frekuensi yang bertujuan untuk memudahkan dalam penyajian data, memudahkan pemahaman dan memudahkan data untuk dibaca yang merupakan sumber informasi dalam penelitian.

Deskripsi ini adalah analisa kepada variabel kompensasi dan disiplin kerja terhadap kinerja karyawan, dimana agar membentuk analisa akan dilakukan berdasarkan hasil pernyatan responden pada setiap variabel. Umar $(2008 ; 201)$ menyatakan bahwa untuk mengintrepertasikan nilaimean dalam frekuensi variabel, maka dapat ditujukan dengan menggunakan interval sebagai berikut :

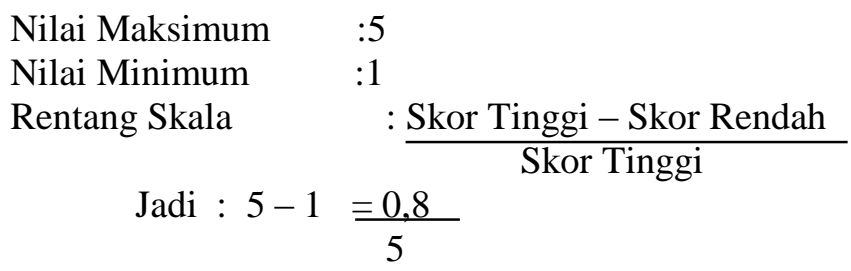

Sehingga diperoleh skala interval, sebagai berikut:

$$
\begin{array}{ll}
1,00-1,80 & =\text { Sangat tidak baik } \\
1,81-2,60 & =\text { Tidak baik } \\
2,61-3,40 & =\text { Ssedang } \\
3,41-4,20 & =\text { Baik } \\
4,21-5,00 & =\text { Sangat baik }
\end{array}
$$

Uji Heterokedastisitas dilakukan agar mengetahui apakah pengamatan dalam regresi terdapat ketidaksamaan variance dari residual satu pengamatan yang tetap homokedastisitas. Hasil pengujian dengan menggunakan analisis dapat dilihat pada gambar berikut ini: 
Scatterplot

Dependent Variable: $Y$

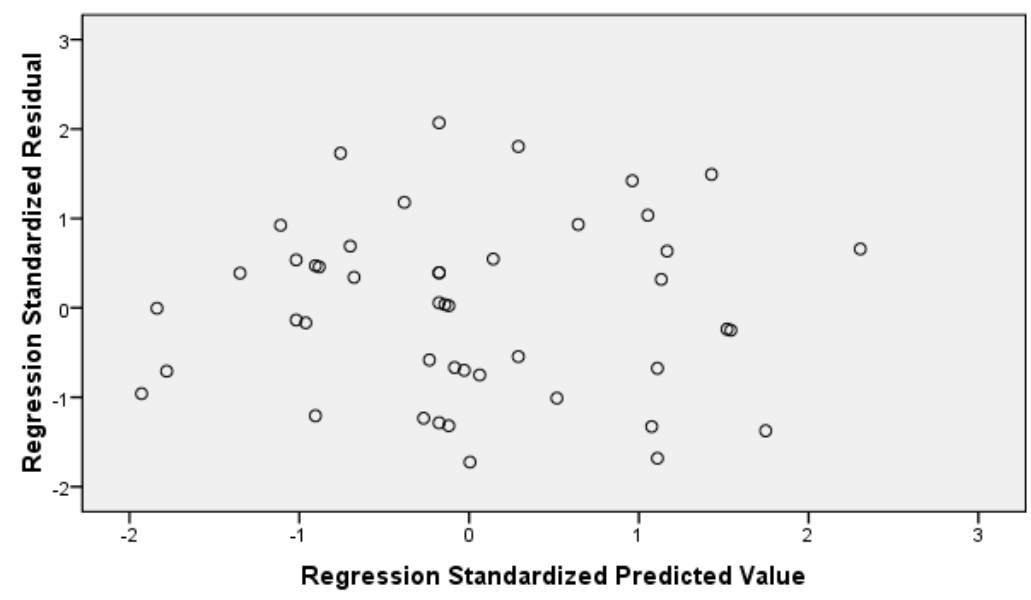

Gambar2. Hasil Uji Heterokedastisitas

Berdasarkan gambar diatas dapat terliuhat bahwa tidak ada pola yang begitu jelas, serta titik-titik menyebar dibawah dan diatas angka 0 pada sumbu $\mathrm{Y}$, dengan demikian pada model regresi diatas tidak terjadi uji Heterokedastisitas.Normalitas bertujuan untuk mengetahui apakah dalam sebuah model regresi variabel dependen (terikat), variabel independen (bebas) atau keduanya memiliki distribusi normal atau tidak. Model regrsi yang baik ialah distribusi data norma atau mendekati normal.

Gambar 3. Hasil Uji Normalitas
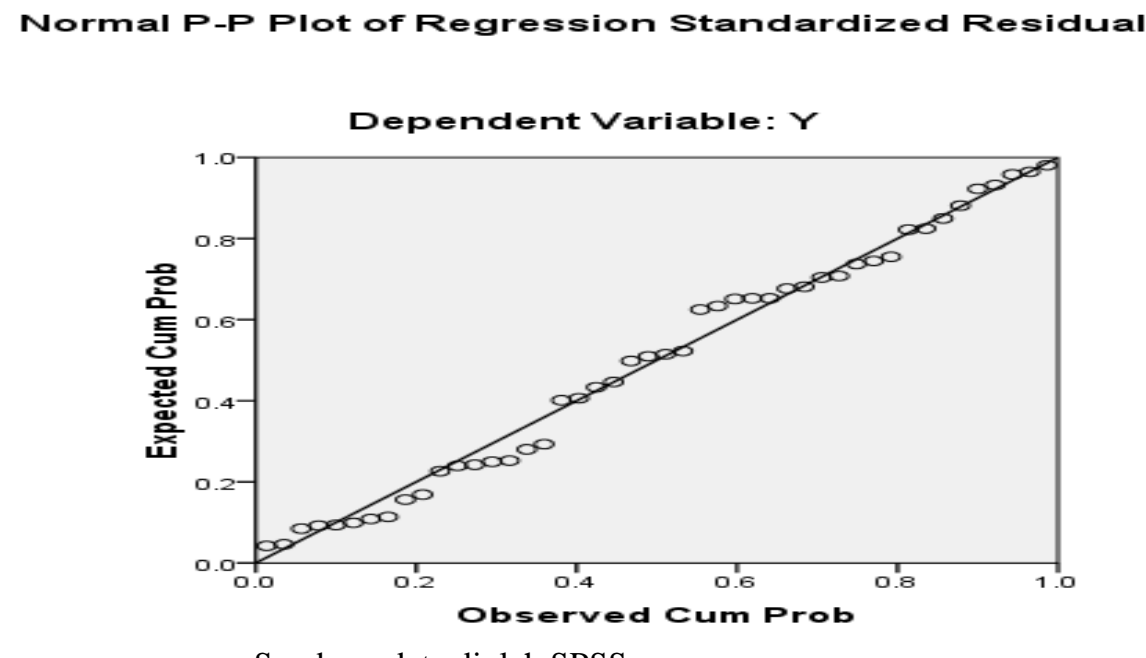

Sumber : data diolah SPSS

Bedasarkan gambar diatas dapat kita dapat menegetahui bahwa distribusi normal yang ditunjukan pada titik-titik yang menyebar dan penyebarannya mengikuti garis diagonal sehingga bisa disimulkan modl regresi mengikuti asumsi normalitas. Menguji dan mengetahui kebenaran hipotesis dalam penelitian yang dilakukan di PT Hadji Kalla Cabang Palu, digunakan metode regresi linear berganda dengan menggunakan SPSS for windows versi 20,0. Hasil analisis tersebut dapat dilihat pada tabel 3 berikut:

Tabel 3. Hasil Regresi Linear Berganda 


\section{Coefficients $^{\mathrm{a}}$}

\begin{tabular}{|c|c|c|c|c|c|c|c|c|c|c|c|}
\hline & & $\begin{array}{l}\text { Unstand } \\
\text { d Coeffi }\end{array}$ & $\begin{array}{l}\text { ardize } \\
\text { cients }\end{array}$ & $\begin{array}{l}\text { Standardized } \\
\text { Coefficients }\end{array}$ & & & & relations & & $\begin{array}{r}\text { Colli } \\
\text { Stat }\end{array}$ & $\begin{array}{l}\text { earity } \\
\text { tics }\end{array}$ \\
\hline & & B & $\begin{array}{l}\text { Std. } \\
\text { Error }\end{array}$ & Beta & & & $\begin{array}{l}\text { Zero- } \\
\text { order }\end{array}$ & Partial & Part & $\begin{array}{l}\text { Toler } \\
\text { ance }\end{array}$ & VIF \\
\hline 1 & (Constant) & 1.210 & .713 & & 1.698 & .097 & & & & & \\
\hline & $\mathrm{X} 1$ & .347 & .130 & .353 & 2.676 & .010 & .367 & .378 & .353 & .998 & 1.002 \\
\hline & $\mathrm{X} 2$ & .333 & 128 & .344 & 2.609 & .012 & .359 & .370 & .344 & .998 & 1.002 \\
\hline
\end{tabular}

Model Summary $^{\mathrm{b}}$

\begin{tabular}{|c|c|c|c|c|c|c|c|c|c|c|}
\hline \multirow{2}{*}{ Model } & \multirow{2}{*}{$\mathrm{R}$} & \multirow{2}{*}{$\begin{array}{c}\mathrm{R} \\
\text { Square }\end{array}$} & \multirow{2}{*}{$\begin{array}{l}\text { Adjusted } \\
\text { R Square }\end{array}$} & \multirow{2}{*}{$\begin{array}{l}\text { Std. Error of } \\
\text { the Estimate }\end{array}$} & \multicolumn{5}{|c|}{ Change Statistics } & \multirow{2}{*}{$\begin{array}{l}\text { Durbin- } \\
\text { Watson }\end{array}$} \\
\hline & & & & & $\begin{array}{l}\text { R Square } \\
\text { Change }\end{array}$ & $\begin{array}{c}\mathrm{F} \\
\text { Change }\end{array}$ & df1 & df2 & $\begin{array}{c}\text { Sig. F } \\
\text { Change }\end{array}$ & \\
\hline 1 & $.503^{\mathrm{a}}$ & .253 & .218 & .24831 & .253 & 7.289 & 2 & 43 & .002 & 1.866 \\
\hline
\end{tabular}

a. Predictors: (Constant), X2,1

b. Dependent Variable: $\mathrm{Y}$

Sumber : data diolah SPSS

Berdasarkan hasil perhitungan pada tabel di atas dapat dirumuskan persamaan regresi linear sebagai berikut:

$$
\begin{aligned}
& \mathbf{Y}=\boldsymbol{\alpha}+\mathbf{b}_{1} \mathbf{X}_{\mathbf{1}}+\mathbf{b}_{2} \mathbf{X}_{\mathbf{2}}+\mathbf{e} \\
& \mathrm{Y}=1,210+0,347\left(\mathbf{X}_{\mathbf{1})}+0,333\left(\mathbf{X}_{\mathbf{2}}\right)+\mathrm{e}\right.
\end{aligned}
$$

Hasil dari fungsi regresi linear berganda vaiabl bebas kompensasi dan disiplin ialah pertanda positif, yang memiliki arti variabel bebas yang dipakai dalam penelitian ini memliki hubungna yang satu arah dengan variabel terikatnya. Bila variabel bebas itu dapat meningkat sehingga akan mendoong terjadinya peningkatan kinerja karyawan dan juga sebaliknya.

Pengaruh signifikan secara serempak maupum secara parsial dari variabel bindependen (kompensasi \& disiplin kerja) terhadap variabel dependen ( kinerja), maka dipakai uji F dan uji t. Pengmbilan keputusan uji hipotesis serempak maupun secara pasial berdsarkan pada angka probalitas yang diperoleh dari hasil pengolahan data lewat program SPSS Statistik Parametrik.

\begin{tabular}{|c|c|c|c|c|c|c|}
\hline & Model & Sum of Squares & Df & Mean Square & $\mathrm{F}$ & Sig. \\
\hline 1 & Regression & ,899 & 2 & ,449 & 7,289 & $.002^{\mathrm{a}}$ \\
\hline
\end{tabular}

\section{ANOVA $^{\mathrm{a}}$}


JURNAL ILMU MANAJEMEN UNIVERSITAS TADULAKO

Vol. 5, No. 3, September 2019, p. 320 - 329

ISSN : 2443-3578 (On Line) / ISSN : 2443-1850 (Print)

\begin{tabular}{|l|r|r|r|r|l|}
\hline Residual & 2,651 & 43 &, 062 & & \\
\hline Total & 3,550 & 45 & & & \\
\hline
\end{tabular}

Sumber : Data diolah oleh SPSS

Tabel 6. Hasil Perhitungan Ujit

Coefficients $^{\mathrm{a}}$

\begin{tabular}{|l|r|r|r|r|r|}
\hline \multirow{2}{*}{ Model } & \multicolumn{2}{|c|}{ Unstandardized Coefficients } & $\begin{array}{c}\text { Standardized } \\
\text { Coefficients }\end{array}$ & \multirow{2}{*}{$\mathrm{T}$} & \multirow{2}{*}{ Sig. } \\
\cline { 2 - 7 } & $\mathrm{B}$ & Std. Error & Beta & &, 000 \\
\hline (Constant) & 1,743 &, 423 & & 4,122 &, 000 \\
\hline Kompensasi &, 299 &, 074 &, 484 & 4,046 &, 000 \\
\hline Disiplin Kerja &, 260 &, 067 &, 465 & 3,886 & \\
\hline
\end{tabular}

Sumber : Data diolah oleh SPSS

Berdasarkan dari hasil di atas dapat diperoleh bahwa: (1) Variabel kompensasi $\left(\mathrm{X}_{1}\right)$, nilai signifikansinya sebesar 0,000 . Angka probabilitas signifikansi < 0,05 sehingga Ho ditolak dan Ha diterima, dengan hasil tersebut kompensasi bepengaruh signifikan terhadap kinerja karyawan pada PT.Hadji Kalla Cabang Palu $\left(\mathrm{X}_{2}\right)$, nilai signifikansinya sebesar 0,000 Karena angka probabilitas signifikansi < 0,05 maka Ho ditolak dan Ha diterima, dengan demikian disiplin kerja berpengaruh signifikan terhadap kinerja karyawan pada PT.Hadji Kalla Cabang Palu.

\section{KESIMPULAN DAN SARAN}

Berdasarkan penelitian yang sudah dilakukan diatas, maka penulis mengambil beberapa kesimpulan dari hasil penelitian ini sebagai berikut : (1) Kompensasi dan disiplin kerja berpengaruh secara serempak dan signifikan terhadap kinerja karywan pada PT. Hadji Kalla Cabang Palu. (2) Kompensasi berpengaruh secara parsial dan signifikan terhadap kinerja karyawan pada PT. Hadji Kalla Cabang Palu. (3) Disiplin kerja berpengaruh secara parsial dan signifikan terhadap kinerja karyawan pada PT. Hadji Kalla Cabang Palu. Berdasarkn hasil penelitian juga hal yang berkaitan dengan kabterbatasan penelitian, maka peneliti mengajukan saran debagai berikut : (1) Hasil penelitian ini dapat dipergunakan sebagai bahan masukan bagi PT. Hadji Kalla Cabang Palu, untuk lebih memperhatikan sistem pemberian kompensasi terutama dalam hal pemberian tunjangan, pemberian tunjangan diberikan perusahaan kepada karyawan masih minimum dan belum sesuai dengan yang diharapkan jika mencapai target, dan juga tunjangan yang diberikan tidak sesuai dengan waktu yang telah ditetapkan. (2) Hendaknya PT. Hadji Kalla Cabang Palu untuk memperhatikan tingkat kedisiplinan moral, karena untuk menaati aturan-aturan yang berlaku harus memiliki kesadaran yang tinggi pada tiap-tiap karyawan. (3) Hendaknya PT. Hadji Kalla Cabang Palu untuk memperhatikan tingkat tanggung jawab, yakni selalu kompak dalam bekerja dan juga bekerja sama dengan sesama karyawan serta hendaknya mempunyai tanggung jawab terhadap hasil agar output yang didapatkan sesuai dengan apa yangdiharapkan. (4) Bagi peneliti berikutnya, didiharapkan agar supaya mengembangkan penelitian ini denagn menggunakan variabel lainyang mempunyai pengaruh terhadap kinerja karyawan. 
JURNAL ILMU MANAJEMEN UNIVERSITAS TADULAKO

Vol. 5, No. 3, September 2019, p. 320 - 329

ISSN : 2443-3578 (On Line) / ISSN : 2443-1850 (Print)

\section{REFERENSI}

Dessler,Gary (2009).ManajemenSumberDayaManusia.Jakarta:Indeks

Ghozali, Imam, (2005). Aplikasi Analisis Multivaiate dengan program SPSS.Semarang:BadanPenerbit UniversitasPonegoro

Ghozali, Imam, (2006). AplikasiAnalisis Multivariate program SPSS. Semarang: BP UniversitasDiponegoro, Semarang.

Hasibuan, H. Melayu S.P, 2014. Manajemen Sumber Daya Manusia Edisi Revisi, Bumi Aksara.Jakarta.

Mangkunegara, AA. Anwar Prabu .,(2009). Evaluasi Kinerja SDM. PT. Refika Aditama, Bandung

Mangkunegara, AA. Anwar Prabu., (2007)PerencanaandanPengembanganSumberDayaManusia . Bandung: RefikaAditama

Riduwan dan Akdom, (2005).Rumus dan Data Dalam Aplikasi Statistik, BandungAlfabeta.

Rivai dan Sagala.2009. Manajemen Sumber Daya Manusia Untuk Perusahaan: Dari Teori Ke Praktek. Raja Grafindi Persada : Jakarta

Soetrisno P.H, (1992). KapitaSelektaEkonomi Indonesia, EdisiKeDuaAndi Offset, Yogyakarta

Sutrisno, Edy2016. ManajemenSumberDayaManusia. Jakarta :Prenadamedia Group

Sugiyono. (2009). MetodePenelitianBisnis (PendekatanKuantitatif, kualitatif dan R\&D). Alfabeta: Bandung.

Sugiyono, 2014. MetodePenelitianBisnis (PendekatanKuantitatif, Kualitatif, dan R\&D). Alfabeta: Bandung.

Sutrisno, Edy2009. ManajemenSumberDayaManusia,EdisiPertama, Kencana : Jakarta. 